\title{
INVERSI BERSAMA GELOMBANG PP DAN PS (JOINT PP AND PS INVERSION) UNTUK MENGANALISA LITOLOGI RESERVOIR
}

\author{
Hafidz Dezulfakar, Firman Syaifuddin, Widya Utama \\ Jurusan Teknik Geofisika, FTSP Institut Teknologi Sepuluh Nopember \\ e-mail:widya@geofisika.its.ac.id
}

\begin{abstract}
Abstrak. Penggunaan gelombang P ( $P$ P wave) dalam eksplorasi seismik kurang mampu menggambarkan litologi khususnya pada daerah yang tersaturasi fluida. Gelombang PS (converted wave) yang merupakan hasil pantulan gelombang $\mathrm{P}$ menjadi gelombang $\mathrm{S}$ telah digunakan untuk mengatasi permasalahan tersebut dengan menggunakan proses inversi yang mengkombinasikan kedua data seismik PP dan PS secara bersamaan (joint inversion). Hasil joint inversion berupa parameter impedansi akustik (impedansi $\mathrm{P})$, impedansi shear (impedansi S), densitas serta parameter turunan yaitu rasio Vp/Vs yang lebih sensitif terhadap litologi dan fluida. Dilakukan dua alur penelitian, alur penelitian pertama menggunakan data seismik PS stack PS time yang harus dilakukan proses konversi domain waktu dari domain PS time menjadi domain PP time. Hasil pada alur penelitian pertama memiliki hasil yang kurang baik dikarenakan adanya keterbatasan pada proses konversi domain. Pada alur penelitian kedua digunakan data seismik PS stack PP time yang menjawab keterbatasan pada alur penelitian pertama. Sehingga didapat hasil inversi berupa parameter impedansi $P$, impedansi $S$, densitas, dan rasio $\mathrm{Vp} / \mathrm{Vs}$ dengan nilai korelasi terhadap sumur secara berturut-turut adalah 0.955339, 0.936588, 0.923806 dan 0.781296. Didapat sebaran litologi sandstone dan shale dari crossplot parameter impedansi P dan impedansi S. Sedangkan litologi reservoir sandstone tersaturasi hidrokarbon didapat dari crossplot antara parameter impedansi $P$ dan rasio $\mathrm{Vp} / \mathrm{Vs}$. Dengan demikian, reservoirsand stone tersaturasi hidrokarbon dapat diperkirakan terletak di antara kedalaman marker sumur beta1 dan MF4 yaitu pada kedalaman sekitar $1350 \mathrm{~ms}$ dan $1400 \mathrm{~ms}$.
\end{abstract}

Kata Kunci: converted wave; konversi domain; litologi, reservoir, rasio Vp/Vs

\begin{abstract}
The usage of P-wave (PP wave) on the seismic exploration provides poor description of subsurface lithological conditions, especially in fluid gas saturated areas. PS-wave (converted wave) which is the result of reflection of P-waves into $S$-waves has been used to solve these problems by using the inversion process which combines with PP and PS seismic data simultaneously (joint inversion). The results of joint inversion are acoustic impedance parameter ( $P$ impedance), shear impedance (S impedance), density and derivative parameter such as $V p / V s$ ratio which more sensitive with lithology and fluids. Has been conducted two flows in this paper, the first flow was using seismic data of PS stack PS time which need to converse first by domain conversion process from PS time domain to be PP time domain. This first flow produces poor results due to the limitations of the domain conversion process. And for the second flow, seismic PS stack PP time was use to solve the limitation of the result from the first flow. The result of the inversion such as parameter of $P$ impedance, $S$ impedance, density, and Vp/Vs ratio with correlation value $0.955339,0.936588,0.923806$ and 0.781296 respectively. The distribution of sandstone and shale lithology distinguished by crossploting the parameter of $P$ impedance and $S$ impedance. Hydrocarbon-saturated sandstone reservoir distinguished by crossploting the parameter of $P$ impedance and Vp/Vs ratio. Thus, the hydrocarbon-saturated sandstone reservoirs can be estimated lies between the depth of marker on the wells beta1 and MF4 which around 1350 ms and 1400 ms.
\end{abstract}

Keywords : converted wave; Vp/Vs ratio; domain conversion; lithology

\section{PENDAHULUAN}

Pada saat energi seismik gelombang $P$ merambat ke dalam permukaan bumi, maka akan terjadi konversi gelombang akibat energi seismik tersebut mengenai batas lapisan, konversi gelombang tersebut berupa gelombang yang dipantulkan dan diteruskan dalam bentuk gelombang $\mathrm{P}$ dan gelombang $\mathrm{S}$. Jika source yang digunakan berupa gelombang $\mathrm{P}$ dan gelombang yang ditangkap oleh geophone berupa gelombang $\mathrm{P}$ maka dinamai gelombang $\mathrm{PP}$, sedangkan jika yang ditangkap oleh geophone berupa gelombang 
S, maka dinamai PS (Fatti dkk, 1994). Pemanfaatan gelombang PP dan PS tersebut sangat berguna dalam eksplorasi hidrokarbon khususnya di dalam menggambarkan litologi reservoir yang tersaturasi fluida. Hal tersebut dikarenakan adanya perbedaan sifat gelombang $\mathrm{P}$ dan gelombang $\mathrm{S}$ saat melewati suatu litologi. Tidak seperti gelombang $P$ yang dapat merambat pada medium fluida, gelombang $S$ justru tidak dapat merambat pada medium fluida sehingga penjalarannya tidak dipengaruhi oleh keberadaan fluida dalam kasus ini khususnya pada litologi reservoir yang tersaturasi fluida. Sehingga jika gelombang $\mathrm{P}$ dan gelombang $\mathrm{S}$ merambat dari suatu litologi yang tidak tersaturasi fluida ke litologi yang tersaturasi fluida maka kecepatan gelombang $\mathrm{P}$ akan menurun sedangkan kecepatan gelombang $S$ tetap. Oleh karena itu, dengan membandingkan nilai kecepatan gelombang $\mathrm{P}$ dan $\mathrm{S}$ (rasio $\mathrm{Vp} / \mathrm{Vs}$ ) dapat memberikan gambaran litologi bawah yang lebih baik. Untuk mendapatkan nilai rasio $\mathrm{Vp} / \mathrm{Vs}$ pada suatu penampang seismik maka dilakukan proses inversi yang mengkombinasikan kedua data seismik PP dan PS secara bersamaan (joint inversion). Rasio $\mathrm{Vp} / \mathrm{Vs}$ merupakan rasio impedansi $\mathrm{P}$ dan impedansi $\mathrm{S}$ dari hasil joint inversion (Simmons dan Backus, 1996 ).

Untuk menganalisa litologi reservoir melalui perbandingan nilai kecepatan gelombang $P$ terhadap gelombang $S(V p / V s$ ratio) maka pada tugas akhir ini dilakukan inversi secara bersamaan pada data seismik PP dan PS (joint PP and PS inversion).

\section{DASAR TEORI}

\section{A. Konversi Gelombang Seismik}

Konversi gelombang adalah perubahan dari suatu tipe gelombang menjadi tipe gelombang lain, peristiwa ini terjadi pada medium interface saat ditransmisikan dan dipantulkan. Dalam kasus seismik eksplorasi, jika gelombang $P$ dari sumber seismik yang datang dengan sudut tertentu mengenai batas perlapisan batuan maka akan terbentuk gelombang pantul berupa gelombang $P$ itu sendiri yang disebut gelombang PP dan gelombang $S$ yang disebut gelombang PS. Terbentuknya gelombang PP disebabkan oleh sifat gelombang $P$ yang memiliki arah pergerakan partikel searah dengan arah penjalaran gelombangnya sehingga partikel medium mengalami kompresi, sedangkan gelombang PS disebabkan oleh sifat gelombang $\mathrm{S}$ yang memiliki arah pergerakan partikel tegak lurus dengan arah penjalaran gelombangnya sehingga partikel medium mengalami puntiran sehingga gelombang yang datang dengan suatu sudut tertebtu akan memantulkan memberikan kompresi dan puntiran pada partikel bidang batas sehingga memantulkan gelombang PP dan PS seperti yang ditunjukkan oleh Gambar 1.

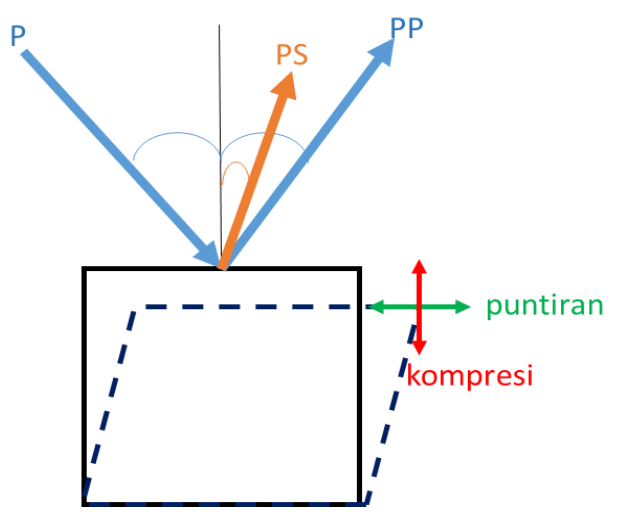

Gambar 1. Konversi Pantulan Gelombang P pada Suatu Medium.

\section{B. Konversi Domain}

Gelombang $P$ memiliki kecepatan yang berbeda dengan kecepatan gelombang $\mathrm{S}$. Kecepatan gelombang $\mathrm{P}$ lebih besar dua kali dari gelombang S (Russell dan Hampson, 2005), maka waktu tempuhnya pun berbeda. Untuk waktu tempuh TWT (two way time) gelombang PS merupakan penjumlahan antara setengah TWT gelombang $\mathrm{P}$ dengan setengah TWT gelombang $\mathrm{S}$ ditunjukkan oleh persamaan (1).

$$
\Delta T W T_{P S}=\frac{\Delta Z}{V_{P}}+\frac{\Delta Z}{V_{S}}=\Delta Z\left(\frac{1}{V_{P}}+\frac{1}{V_{S}}\right)
$$

dengan:

$\mathrm{V}_{\mathrm{P}} \quad=$ cepat rambat gelombang $\mathrm{P}(\mathrm{m} / \mathrm{s})$

$\mathrm{V}_{\mathrm{S}} \quad=$ cepat rambat gelombang $\mathrm{S}(\mathrm{m} / \mathrm{s})$

$\mathrm{Z}=$ kedalaman lapisan $(\mathrm{m})$ 
Dapat disimpulkan bahwa seismik PP dan PS pada suatu event akan memiliki posisi yang berbeda terhadap kedalaman. Agar event tersebut memiliki TWT yang sama atau domain waktu yang sama, maka perlu dilakukannya proses konversi domain yang mengubah TWT PS menjadi TWT PP. Persamaan (2) merupakan fungsi hubungan TWT gelombang PS menjadi TWT gelombang P.

$$
P t w t_{-} e s t(z)=P S t w t(z)-\frac{S t w t_{-} e s t(z)-P t w t(z)}{2}
$$

dengan:

$$
\begin{array}{ll}
\text { Ptwt_est }(\mathrm{z}) & =\text { estimasi TWT gelombang } \mathrm{P} \text { dari } \\
& \text { gelombang PS }(\mathrm{ms}) \\
\text { PStwt }(\mathrm{z}) & =\text { TWT gelombang PS }(\mathrm{ms}) \\
\text { Stwt_est }(\mathrm{z}) & =\text { TWT gelombang } \mathrm{S}(\mathrm{ms}) \\
\text { Ptwt }(\mathrm{z}) & =\text { TWT gelombang } \mathrm{P}(\mathrm{ms})
\end{array}
$$

Dengan menghitung selisih antara TWT gelombang $P$ dengan TWT gelombang $P$ hasil estimasi menggunakan persamaan (2), maka didapat nilai time difference (Dt) yang ditunjukkan oleh persamaan (3). Nilai DT tersebut digunakan dalam mengoreksi nilai TWT gelombang $S$ pada persamaan (4) untuk mendapatkan nilai TWT gelombang $\mathrm{P}$ dari TWT gelombang PS sehingga dapat dilakukan konversi domain.

$$
\begin{gathered}
D t(z)=P t w t(z)-P t w t_{-} e s t(z) \\
P t w t(z)=P S t w t(z)-\frac{\left(S t w t_{-} e s t(z)-2 D T(z)\right)-P t w t(z)}{2}
\end{gathered}
$$

\section{Inversi Bersama Gelombang PP dan PS (Joint Inversion PP-PS)}

Inversi bersama gelombang PP dan PS (Joint Inversion $P P$ and $P S$ ) dilakukan dengan input data seismik PP dan PS secara bersamaan di dalam proses inversinya untuk mengestimasi nilai Zp, Zs dan $\rho$. Teori inversi bersama gelombang PP dan PS diawali dengan menganggap bahwa suatu trace sesimik merupakan hasil konvolusi antara reflesivitas dengan wavelet.

$$
\mathrm{S}=\mathrm{W} * \mathrm{R}
$$

dengan:

Rt $=$ koefisien refleksifitas

$\mathrm{Wt}=$ inversi wavelet

St $=$ seismic trace

Selanjutnya dengan menggunakan persamaan Aki-Richards yang memberikan hubungan besarnya nilai koefisien refleksi terhadap parameter fisik batuan seperti kecepatan (2) Jn densitas. Dimodifikasi oleh Fatti dkk. dengan memisahkan koefisien refleksi gelombang $\mathrm{P}$ dan $\mathrm{S}$ berupa:

$$
R_{P P}(\theta)=c_{1} R_{P}+c_{2} R_{S}+c_{3} R_{D}
$$

dengan:

$c_{1}=1+\tan ^{2} \vartheta$

$c_{2}=-8 \gamma^{2} \sin ^{2} \vartheta$

$c_{3}=-0.5 \tan ^{2} \vartheta+{ }^{2} \gamma^{2} \sin ^{2} \vartheta$

$\gamma=V_{S} / V_{P}$,

Russel dan Hampson mengembangkan hasil kerja Simmons dan Backus tentang linearisasi refleksivitas $P\left(R_{P}\right)$, refleksivitas $S \quad\left(R_{S}\right)$ dan refleksivitas densitas $\left(R_{D}\right)$, berupa:

$$
\begin{aligned}
& R_{P}=\frac{1}{2}\left[\frac{\Delta V_{P}}{V_{P}}+\frac{\Delta \rho}{\rho}\right]=\frac{\Delta Z_{P}}{2 Z_{P}} \\
& R_{S}=\frac{1}{2}\left[\frac{\Delta V_{S}}{V_{S}}+\frac{\Delta \rho}{\rho}\right]=\frac{\Delta Z_{S}}{2 Z_{S}} \\
& R_{D}=\frac{\Delta \rho}{\rho}
\end{aligned}
$$

Pendekatan Buland dan Omre memberikan sebuah pendekatan yang mampu melakukan inversi secara langsung impedansi $P\left(Z_{P}\right)$, impedansi $S\left(Z_{S}\right)$, dan densitas ( $\rho)$ seperti yang ditunjukkan oleh persamaan berikut:

$\frac{\Delta V_{P}}{V_{P}} \approx \Delta \ln V_{P}$

Kemudian diperkenalkan variabel yang baru yaitu $L_{p}=\ln \left(Z_{p}\right)$, yakni logaritma natural dari impedansi akustik untuk mentransformasikan 
persamaan refleksivitas tersebut menjadi impedansi, sehingga refleksivitas $R_{p}$ pada persamaan (7) dapat dinyatakan menjadi:

$R_{P i} \approx \frac{1}{2} \Delta \ln Z_{P i}=\frac{1}{2}\left[\ln Z_{P i+1}-\ln Z_{P i}\right]$

dengan i merupakan permukaan refleksi antara lapisan i dan i+1. Dengan menganggap banyaknya refleksi $\mathrm{N}$ sehingga persamaan (11) dapat dinyatakan dengan matrik berikut:

$$
\left[\begin{array}{c}
R_{P 1} \\
R_{P 2} \\
\vdots \\
R_{P N}
\end{array}\right]=\frac{1}{2}\left[\begin{array}{cccc}
-1 & 1 & 0 & \cdots \\
0 & -1 & 1 & \ddots \\
0 & 0 & -1 & \ddots \\
\vdots & \ddots & \ddots & \ddots
\end{array}\right]\left[\begin{array}{c}
L_{P 1} \\
L_{P 2} \\
\vdots \\
L_{P N}
\end{array}\right]
$$

dengan:

$\mathrm{Ri}=$ refleksivitas

$\mathrm{L}_{\mathrm{p}} \mathrm{i} \quad=$ logaritma natural dari impedansi akustik

Setelah itu, ditambahkan efek wavelet dengan menganggap bahwa trace seismik merupakan hasil konvolusi dari wavelet dengan refleksivitas menggunakan matriks wavelet sebagai berikut:

$\left[\begin{array}{c}S_{1} \\ S_{2} \\ \vdots \\ S_{N}\end{array}\right]=\left[\begin{array}{cccc}w_{1} & 0 & 0 & \cdots \\ w_{2} & w_{1} & 0 & \ddots \\ w_{3} & w_{2} & w_{1} & \ddots \\ \vdots & \ddots & \ddots & \ddots\end{array}\right]\left[\begin{array}{c}R_{P 1} \\ R_{P 2} \\ \vdots \\ R_{P N}\end{array}\right]$

dengan:

$\mathrm{Si} \quad=$ trace seismik

wi = wavelet

$\mathrm{Ri} \quad=$ refleksivitas

Sehingga dari persamaan (12) dan (13) didapat:

$$
S=(1 / 2) W D L_{P}
$$

W adalah matriks wavelet pada persamaan (14) dan $D$ adalah matrik derivatif dari persamaan (12). Dengan mengkombinasikan persamaan (6) dengan persamaan (14) maka didapat:

$S(\theta)=(1 / 2) c_{1} W(\theta) D L_{P}+(1 / 2) c_{2} W(\theta) D L_{S}+W(\theta) c_{3} D L_{D}$
Persamaan (15) tersebut dapat dipergunakan untuk inversi dengan syarat terdapat relasi antara parameter impedansi dengan densitas. Relasi antara impedansi $\mathrm{P}$, impedansi $\mathrm{S}$ dan densitas [3] adalah sebagai berikut:

$$
\begin{aligned}
& \ln \left(Z_{S}\right)=k \ln \left(Z_{P}\right)+k_{c}+\Delta L_{S} \\
& \ln \left(Z_{D}\right)=m \ln \left(Z_{P}\right)+m_{c}+\Delta L_{D}
\end{aligned}
$$

Koefisien $k, k_{c}, m$, dan $m_{c}$ ditentukan dari analisis log sumur pada daerah tersebut. Hubungan tersebut juga dapat digambarkan dengan crossplot seperti pada Gambar 2.
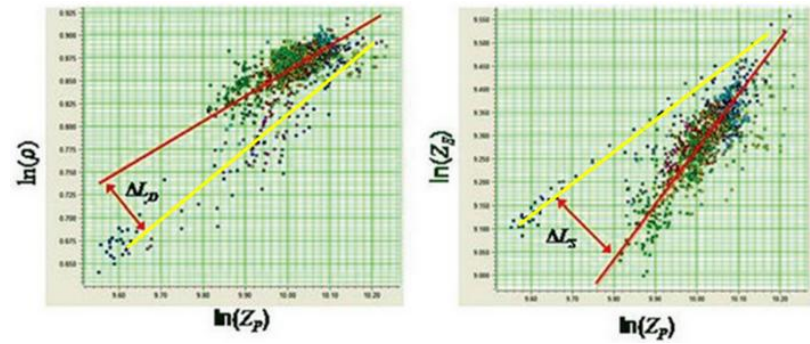

Gambar 2. Crossplot antara In( $\rho)$ terhadap $\operatorname{In}(Z \mathrm{p})$ dan $\ln (Z s)$ terhadap $\ln (Z \mathrm{p})$ (Russel Software Service).

Gambar 2 merupakan crossplot hubungan data sumur $\ln (\rho)$ terhadap $\ln (Z p)$ dan $\ln (Z s)$ terhadap $\ln (Z p)$. Garis kuning menunjukkan bahwa adanya deviasi garis trend masing-masing data sumur pada crossplot yang menyatakan adanya anomali fluida (Russel Software Service).

Dengan mengkombinasi persamaan (15), (16), dan (17) serta diubah dalam bentuk matriks sehingga menjadi seperti berikut:

$$
\left[\begin{array}{c}
S\left(\theta_{1}\right) \\
S\left(\theta_{2}\right) \\
\vdots \\
S\left(\theta_{N}\right)
\end{array}\right]=\left[\begin{array}{ccc}
\tilde{c}_{1} W\left(\theta_{1}\right) D & \tilde{c}_{2} W\left(\theta_{1}\right) D & c_{3} W\left(\theta_{1}\right) D \\
\tilde{c}_{1} W\left(\theta_{2}\right) D & \tilde{c}_{2} W\left(\theta_{2}\right) D & c_{3} W\left(\theta_{2}\right) D \\
\vdots & \vdots & \vdots \\
\tilde{c}_{1} W\left(\theta_{N}\right) D & \tilde{c}_{2} W\left(\theta_{N}\right) D & c_{3} W\left(\theta_{N}\right) D
\end{array}\right]\left[\begin{array}{c}
L_{P} \\
\Delta L_{S} \\
\Delta L_{D}
\end{array}\right]
$$

Dikarenakan joint inversion PP dan PS ini yang bukan hanya menggunakan masukan data seismik PP saja tetapi juga secara bersamaan menggunakan data seismik PS, maka untuk data seismik PS teorinya adalah sebagai berikut dengan menggunakan persamaan linear Aki Richard dan 
Frasier (Aki dan Richards, 2002, Richards dan Frasier, 1976) yang ditunjukkan oleh Margrave dkk.

$R_{P S}(\theta, \varphi)=c_{4} R_{S}+c_{5} R_{D}$

dengan:

$$
\begin{aligned}
& c_{4}=-\tan \varphi\left[4 \gamma \sin ^{2} \theta-4 \cos \theta \cos \varphi\right] \\
& c_{5}=\tan \varphi\left[\frac{1}{2 \gamma}+\gamma \sin ^{2} \varphi-\cos \theta \cos \varphi\right]
\end{aligned}
$$

Sama dengan seismik PP sebelumnya dengan menggunakan pendekatan refleksivitas pada persamaan (7) dan (8) maka persamaan (19) menjadi :

$$
S_{P S}(\theta)=\frac{c_{4}}{2} W(\theta) D L_{S}+c_{5} W(\theta) D L_{D}
$$

Sehingga didapat matriks akhir inversi bersama PP dan PS dengan mengkombinasikan persamaan matriks (18) dan persamaan (20) sebagai berikut:

$$
\left[\begin{array}{c}
S_{P p}\left(\boldsymbol{\theta}_{1}\right) \\
\vdots \\
S_{P P}\left(\boldsymbol{\theta}_{N}\right) \\
S_{P S}\left(\boldsymbol{\theta}_{1}\right) \\
\vdots \\
S_{P S}\left(\boldsymbol{\theta}_{M}\right)
\end{array}\right]=\left[\begin{array}{ccc}
\tilde{c}_{1}\left(\boldsymbol{\theta}_{1}\right) W\left(\boldsymbol{\theta}_{1}\right) D & c_{2}\left(\boldsymbol{\theta}_{1}\right) W\left(\boldsymbol{\theta}_{1}\right) D & c_{3}\left(\boldsymbol{\theta}_{1}\right) W\left(\boldsymbol{\theta}_{1}\right) D \\
\vdots & \vdots & \vdots \\
\tilde{c}_{1}\left(\boldsymbol{\theta}_{N}\right) W\left(\boldsymbol{\theta}_{N}\right) D & c_{2}\left(\boldsymbol{\theta}_{N}\right) W\left(\boldsymbol{\theta}_{N}\right) D & c_{3}\left(\boldsymbol{\theta}_{N}\right) W\left(\boldsymbol{\theta}_{N}\right) D \\
\tilde{c}_{4}\left(\boldsymbol{\theta}_{1}\right) W\left(\boldsymbol{\theta}_{1}\right) D & \frac{c_{+}\left(\boldsymbol{\theta}_{1}\right)}{2} W\left(\boldsymbol{\theta}_{1}\right) D & c_{5}\left(\boldsymbol{\theta}_{1}\right) W\left(\boldsymbol{\theta}_{1}\right) D \\
\vdots & \vdots & \vdots \\
\tilde{c}_{4}\left(\boldsymbol{\theta}_{M}\right) W\left(\boldsymbol{\theta}_{M}\right) D & \frac{c_{+}\left(\boldsymbol{\theta}_{M}\right)}{2} W\left(\boldsymbol{\theta}_{M}\right) D & c_{5}\left(\boldsymbol{\theta}_{M}\right) W\left(\boldsymbol{\theta}_{M}\right) D
\end{array}\right]\left[\begin{array}{c}
L_{P} \\
\Delta L_{S} \\
\Delta L_{D}
\end{array}\right]
$$

Persamaan (21) tersebut telah mengkombinasikan masukan data PP dan PS di dalam matriksnya.

Selanjutnya dilakukan iterasi dengan tebakan awal berupa model awal impedansi $\mathrm{P}$ (Russel Software Service). Metode iterasi menggunakan metode gradien konjugasi. Metode gradien konjugasi merupakan metode untuk meminimalkan suatu fungsi yang arah pencarian pertamanya mengambil arah penurunan tercuram (steepest descent). Metode ini menggunakan arah pencarian yang saling ortogonal serta gradien yang selalu diperbarui pada setiap langkah iterasi yang diawali oleh nilai awal masukan, sehingga pada setiap iterasi akan bergerak maju menuju penyelesaian yang optimal. Dalam penelitian ini model awal berupa nilai impedansi $P$ pada kasus litologi tanpa fluida yang ditunjukkan oleh nilai $\Delta \mathrm{L}_{s}$ dan $\Delta \mathrm{L}_{D}$ bernilai nol yang menandakan tidak adanya garis trend fluida yang terpisah seperti yang ditunjukkan oleh Gambar 2 sebelumnya. Model awal tersebut ditunjukkan oleh persamaan (22).

$$
\left[\mathrm{L}_{\mathrm{P}} \Delta \mathrm{L}_{\mathrm{S}} \Delta \mathrm{L}_{\mathrm{D}}\right]^{\mathrm{T}}=\left[\ln \left(\mathrm{Z}_{\mathrm{PO}}\right) 00\right]^{\mathrm{T}} .
$$

Setelah dilakukan iterasi maka didapat nilai impedansi $\mathrm{P}$, impedansi $\mathrm{S}$ dan densitas dengan menggunakan persamaan (23) dikarenakan bentuk hubungannya telah dijelaskan pada persamaan (16) dan (17).

$$
\begin{aligned}
& Z_{P}=\exp \left(L_{P}\right) \\
& Z_{S}=\exp \left(k L_{P}+k_{c}+\Delta L_{S}\right) \\
& \rho=\exp \left(m L_{P}+m_{c}+\Delta L_{D}\right)
\end{aligned}
$$

\section{METODE PENELITIAN}

Tahap awal sebelum inversi adalah dengan membuat model awal kecepatan dari data sumur yang diinterpolasikan mengikuti pola bentuk horizon yang telah di-picking sebelumnya. Model awal tersebut digunakan untuk proses konversi domain waktu seismik PS menjadi domain waktu seismik PP dikarenakan oleh adanya perbedaan waktu tempuh antara gelombang PP dan PS. Selanjutnya dilakukan peningkatan kualitas konversi domain dengan menyesuaikan event PS yang ditunjukkan oleh horizon pada data seismik PS dengan event PP yang ditunjukkan oleh horizon pada data seismik PP. Setelah itu dilakukan proses joint inversion. Selajutnya dilakukan analisa litologi dengan melakukan crossplot impedansi $\mathrm{P}$ dengan impedansi $S$ serta impedansi $P$ dengan rasio Vp/Vs. Pada penelitian ini dilakukan dua alur penelitian. Pada alur penelitian pertama yang ditunjukkan oleh Gambar 4 dilakukan proses inversi dengan input seismik PP dan PS yang sebelumnya telah dilakukan proses konversi domain waktu PS menjadi waktu PP Sedangkan pada alur penelitian kedua tidak dilakukanya tahapan proses konversi domain dikarenakan seismik PS yang digunakan sebagai inputan proses inversi sudah di dalam domain waktu gelombang PP. 


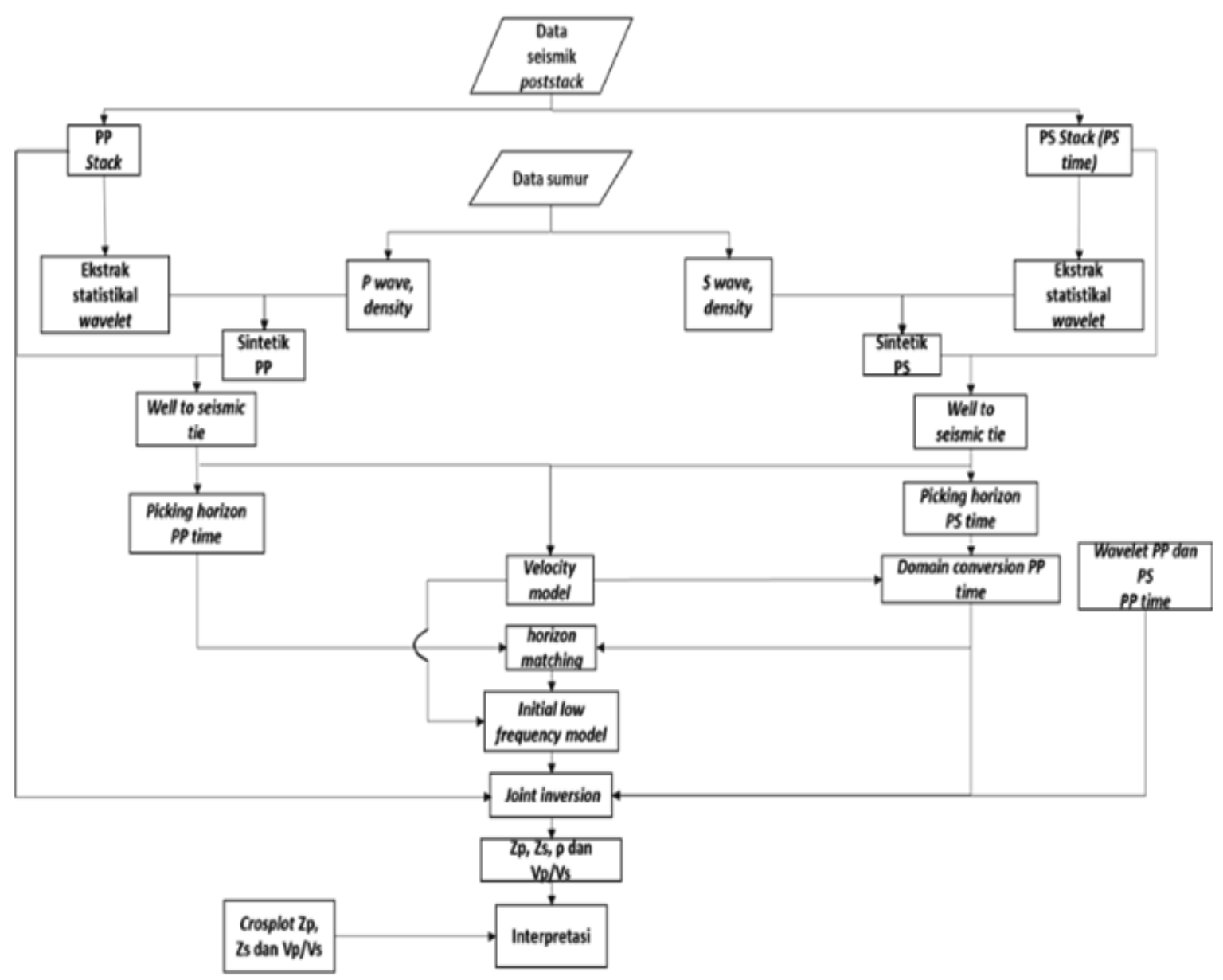

Gambar 4. Diagram Alur Proses Penelitian Pertama.

\section{HASIL DAN ANALISA}

Hasil pada alur penelitian pertama dinyatakan tidak valid dikarenakan oleh keterbatasan pada tahapan pembuatan model kecepatan untuk proses konversi domain yang hanya menggunakan satu buah data sumur yang diinterpolasikan keseluruh penampang seismik. Sehingga model kecepatan tidak mewakili kecepatan yang sebenarnya, yang mengakibatkan event seismik PP dan PS tidak sesuai. Hal tersebut ditunjukkan oleh penampang hasil inversi impedansi $S$ secara keseluruhan, maka pada dua lokasi yang ditunjukkan oleh lingkaran putih pada Gambar 5 terdapat adanya anomali yang ganjil.

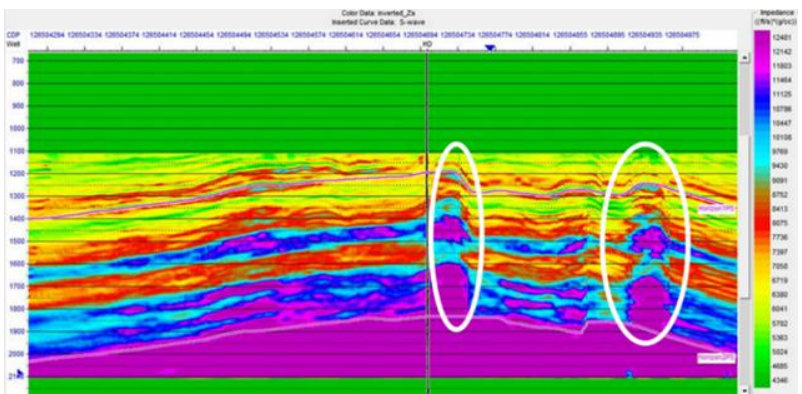

Gambar 5. Penampang Impedansi S Hasil Inversi Alur Penelitian Pertama. 


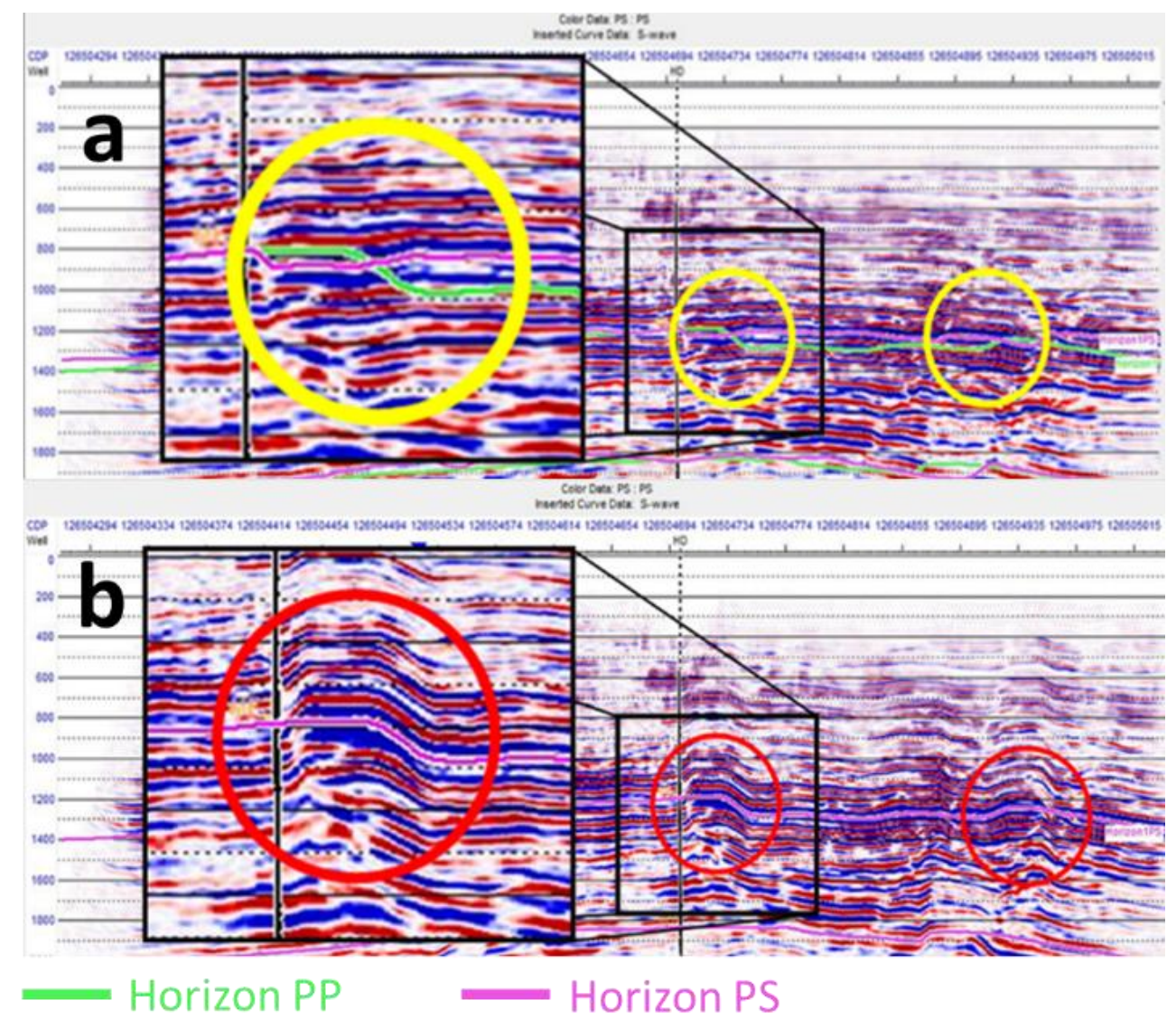

Gambar 6. a) Perbedaan Event Seismik PP dan PS,

b) Setelah Dilakukan Proses Event Matching.

Adanya anomali ganjil tersebut dikarenakan oleh proses event matching yang di dalam prosesnya melakukan penarikan time event seismik PS stack PS time mengikuti bentuk event seismik PP stack PP time. Adanya perbedaan event horizon antara kedua data tersebut yang ditunjukkan oleh lingkaran kuning pada Gambar 6a sehingga saat dilakukannya proses event matching maka bentuk event seismik PS stack PS time ditarik mengikuti event seismik PP stack PP time seperti yang ditunjukkan oleh Gambar 6b.

Pada alur penelitian kedua digunakan data seismik PS stack PP time yang menjawab keterbatasan pada alur penelitian pertama. Sehingga didapat hasil inversi yang valid berupa parameter impedansi $\mathrm{P}$, impedansi $\mathrm{S}$, densitas, dan rasio $\mathrm{Vp} / \mathrm{Vs}$ dengan nilai korelasi terhadap sumur secara berturut-turut adalah 0.955339, 0.936588,
0.923806 dan 0.781296. Penampang rasio Vp/Vs yang didapat dari perbandingan impedansi $P$ dengan impedansi $\mathrm{S}$ tersebut ditunjukkan oleh Gambar 7 yang menunjukkan variasi litologi yang jelas, namun belum dapat menunjukkan jenis litologinya.

Selanjutnya dilakukan analisa litologi dengan melakukan uji sensitivitas sumur. Tahapan pertama adalah dengan menganalisa langsung terhadap log data sumur volume clay dan porositas yang ditunjukkan oleh Gambar 8. Pada kedalaman horizon1 sampai horizon2 sangat jelas menunjukkan adanya perbedaan normalitas log antara kedalaman horizon1 sampai beta1 dengan yang berada pada kedalaman beta1 sampai MF4. Pada kedalaman horizon1 sampai beta1 memiliki nilai normal porositas yang lebih besar daripada data log porositas pada kedalaman beta1 sampai 
MF4, begitu juga dengan yang ditunjukkan oleh log volume clay yang menunjukkan kedua rentang kedalaman tersebut memiliki nilai normal yang berbeda. Perbedaan normalitas nilai log tersebut disebabkan oleh proses sedimentasi dan pengendapan. Uji sensitivitas dilakukan pada kedalaman beta1 sampai MF4 dikarenakan adanya anomali yang kontras pada rentang kedalaman tersebut. Sedangkan pada kedalaman horizon1 sampai beta1 tidak dapat menunjukkan anomali.

Pada Gambar 8, adanya anomali pada rentang kedalaman beta1 sampai MF4 yaitu seperti yang ditunjukkan oleh kotak berwarna hitam. Anomali tersebut memiliki nilai volume clay yang rendah dan porositas yang tinggi. Anomali tersebut dapat dikatakan lapisan sandstone dikarenakan sandstone memiliki kandungan clay yang rendah serta memiliki porositas yang besar.

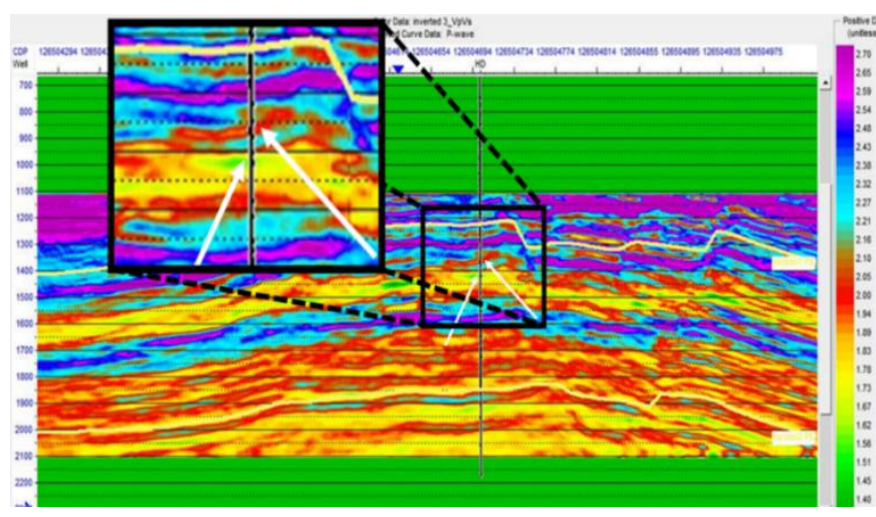

Gambar 7. Penampang Rasio Vp/Vs Hasil Inversi Alur Penelitian Kedua.

Oleh karena uji sensitivitas dilakukan pada rentang kedalaman tersebut. Gambar 9a menunjukkan crossplot antara data sumur volume clay dan porositas pada kedalaman beta1 sampai MF4. Terlihat adanya dua zona yang terpisah yang menandakan perbedaan litologi. Zona pertama yang ditunjukkan oleh warna kuning memiliki porositas yang tinggi yaitu berada dalam rentang 0.3 sampai $0.37 \%$ dan nilai volume clay yang sangat rendah yaitu berada dalam rentang 0 sampai 0.2 sehingga zona yang berwarna kuning tersebut diinterpretasikan sebagai zona litologi sandstone. Zona kedua adalah zona yang ditunjukkan oleh warna abu-abu yang memiliki nilai porositas yang lebih rendah dan volume clay yang lebih tinggi daripada zona litologi sandstone. Zona tersebut dapat diinterpretasikan sebagai litologi shale.

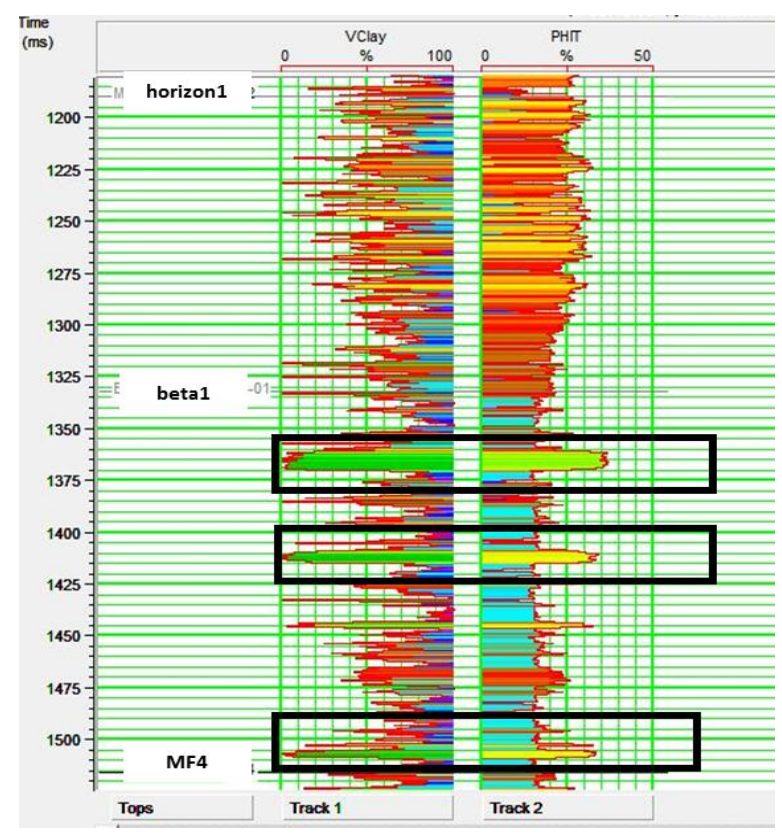

Gambar 8. Data Sumur Volume Clay dan Porositas pada Dua Rentang Kedalaman Horizon1 sampai beta1 dan beta1 sampai MF4.

Selanjutnya untuk mengetahui hubungan kedua litologi tersebut dengan parameter impedansi P dan impedansi S maka uji sensitivitas selanjutnya dilakukan crossplot antara data log impedansi $\mathrm{P}$ dengan impedansi $\mathrm{S}$ dengan skala warna berupa nilai log porositas seperti yang ditunjukkan oleh Gambar 9b. Terdapat dua zona yang terpisah yang menandakan adanya perbedaan litologi yang jelas. Zona pertama adalah zona yang berwarna kuning yang memiliki nilai impedansi $P$ yang rendah yaitu berada dalam rentang 4250 sampai $5000((\mathrm{~m} / \mathrm{s})(\mathrm{g} / \mathrm{cc}))$ dan nilai impedansi $\mathrm{S}$ yang rendah dengan rentang 2100 sampai 2600 $((\mathrm{m} / \mathrm{s})(\mathrm{g} / \mathrm{cc}))$. Zona tersebut juga memiliki nilai porositas yang sama dengan batas porositas pada zona crossplot pada Gambar 9a yaitu 0.3 sampai 0.37 yang ditandai dengan warna data hijau sesuai dengan skala warna porositas pada crossplot. Sehingga dapat disimpulkan bahwa zona yang berwarna kuning tersebut merupakan zona litologi 
sandstone. Sedangkan zona kedua berwarna abuabu tersebut merupakan zona litologi shale.

Uji sensitivitas selanjutnya adalah dengan melakukan crossplot data log impedansi P terhadap nilai rasio $\mathrm{Vp} / \mathrm{Vs}$ seperti yang ditunjukkan oleh Gambar 9c. Uji sensitivitas ini bertujuan untuk menentukan zona dengan kandungan hidrokarbon. Didapat zona yang terpisah dengan kontrol nilai porositas 0.3 sampai 0.37 sebagai skala warna. Zona tersebut berwarna merah yang terpisah cukup jelas dengan nilai rentang impedansi $P$ rendah yang sama dengan crossplot pada Gambar 9b, yaitu sekitar 4250 sampai $5000((\mathrm{~m} / \mathrm{s})(\mathrm{g} / \mathrm{cc}))$ dan nilai rasio $\mathrm{Vp} / \mathrm{Vs}$ yang juga rendah.

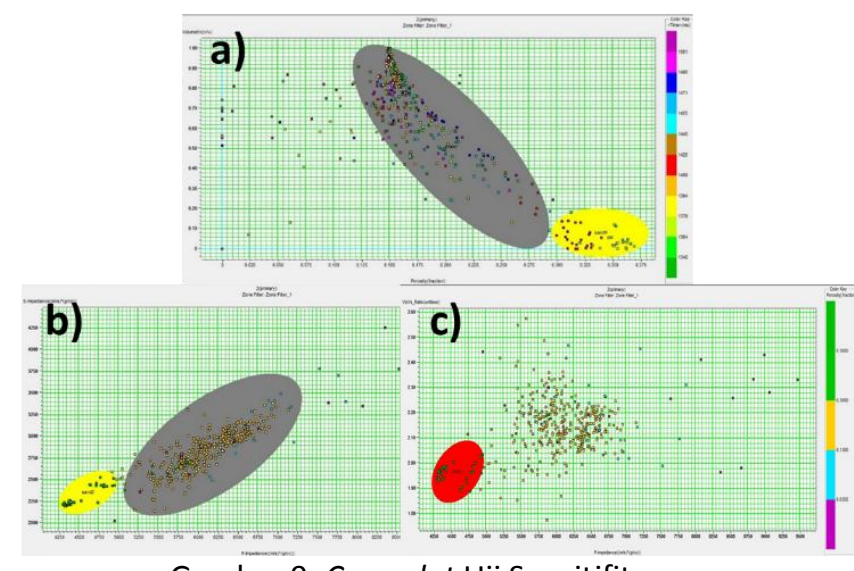

Gambar 9. Crossplot Uji Sensitifitas.

a) Porositas (Sumbu $x$ ) dengan Volume Caly (Sumbu y), b) Impedansi $P$ (sumbu $x$ ) dengan Impedansi S (sumbu y), b) Impedansi $P$ (sumbu $x$ ) dengan Rasio Vp/Vs (Sumbu y) dengan Skala Warna Berupa Nilai Log Porositas.

Sehingga dengan mengaplikasikan pola uji sensitifitas pada Gambar 9b dan 9c terhadap data hasil inversi yang berupa impedansi $P$, impedansi $S$ dan rasio $\mathrm{Vp} / \mathrm{Vs}$ didapat sebaran litologi sandstone dan shale dan litologi gas sand reservoir.

Dengan demikian, didapat litologi sandstone dan shale yang tersebar mengikuti pola horizon pada kedalaman beta1 sampai MF4 seperti yang ditunjukkan oleh Gambar 10a. Litologi sandstone ditunjukkan oleh warna kuning sedangkan shale ditunjukkan oleh warna abu-abu. Jika dilihat pada sekitar sumur yang berwarna biru, maka litologi sandstone berada pada kedalaman sekitar $1350 \mathrm{~ms}$ dan $1400 \mathrm{~ms}$. Sedangkan untuk melihat litologi sandstone tersaturasi hidrakarbon yang berupa gas pada Gambar 10b ditunjukkan oleh warna merah. Jika dilihat di sekitar sumur yang berwarna biru, maka litologi sandstone tersaturasi hidrokarbon gas berada pada kedalaman sekitar 1350 ms dan 1400 ms.

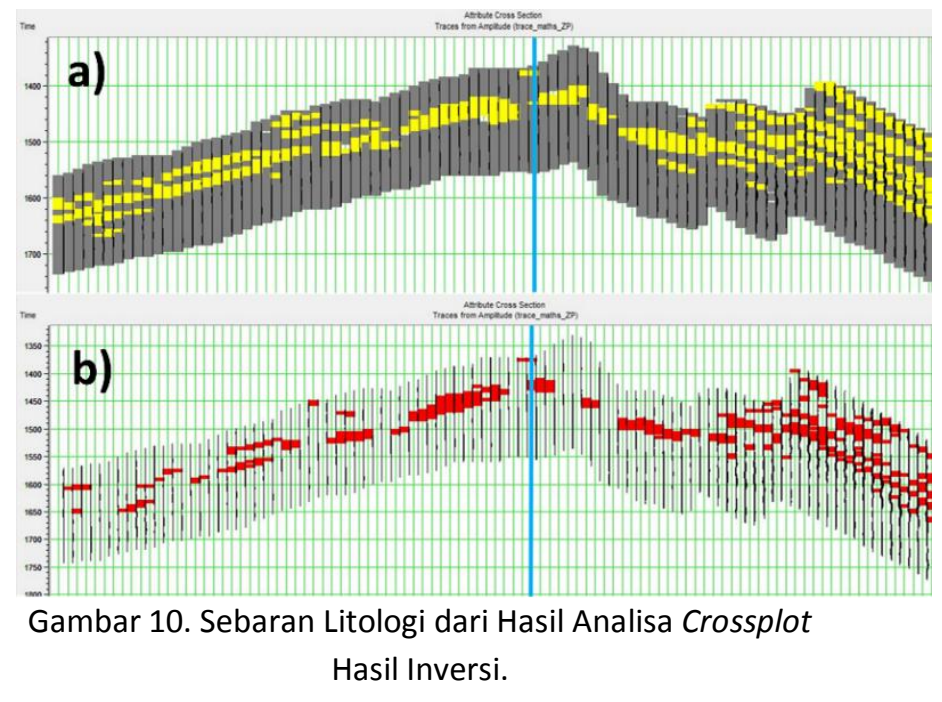

a) Sandstone (Kuning), Shale(Abu-abu),

b) Gas sand Reservoir (Merah).

\section{PENUTUP}

\section{Kesimpulan}

Kesimpulan yang dapat diperoleh dari tugas akhir ini adalah:

$>$ Proses konversi domain merupakan tahapan yang sangat penting sebelum dilakukannya proses joint PP and PS inversion. Jika event antara seismik PP dan PS tidak matching maka akan memberikan hasil inversi yang buruk.

$>$ Hasil joint inversion dengan menggunakan alur penelitian kedua lebih baik dikarenakan data seismik PS yang digunakan telah dilakukan konversi domain dengan menggunakan model kecepatan yang didapat saat proses pengolahan data seismik yang mencakupi seluruh penampang seismik dan tidak hanya diwakilkan oleh data sumur.

$>$ Nilai rasio $\mathrm{Vp} / \mathrm{Vs}$ dari perbandingan nilai hasil joint inversion impedansi $\mathrm{P}$ dan impendasi $\mathrm{S}$ sangat baik digunakan untuk menganalisa litologi reservoir. 
Dari parameter hasil joint inversion dengan mengikuti pola crossplot dari proses uji sensitivitas sumur didapat sebaran litologi sandstone, shale dan sandstone tersaturasi hidrokarbon gas.

\section{Saran}

$>$ Konversi domain sebaiknya menggunakan model kecepatan dari hasil proses pengolahan data seismik.

$>$ Perlu dilakukanya analisis fasies seismik lebih lanjut dan data geologi lapangan penelitian untuk mengetahuin proses pengendapan secara detail.

\section{DAFTAR PUSTAKA}

Buland, A. and Omre, H., 2003. Bayesian linearized AVO inversion. Geophysics, 68, 185-198.

Fatti, J., Smith, G., Vail, P., Strauss, P., and Levitt, P., 1994. Detection Of Gas In Sandstone Reservoirs Using AVO Analysis: A 3D Seismic Case History Using The Geostack Technique. Geophysics, 59, 1362-1376.

Margrave, G.F., Stewart, R. R. and Larsen, J. A., 2001. Joint PP and PS Seismic Inversion: The Leading Edge, 20, no. 9,1048-1052.

Russell, B. and Hampson, D., 2005. Joint Simultaneous Inversion of PP and PS Angle Gathers: SEG Annual Meeting, 6-11 November, Houston, Texas.

Russel Software Service, Ltd., 2000. ProMC Tutorial.

Simmons, J.L. and Backus, M.M., 1996. Waveform-based AVO Inversion and AVO Prediction-Error: Geophysics, 61, 1575-1588. 